\title{
Research Station in the Jordan Desert
}

\author{
By J. B. Nelson
}

The FPS Council last October allocated 1500 from the FPS/WWF Revolving Fund towards the purchase of buildings for the Azraq International Biological Station of which, as announced in ORYX in May 1968, Dr Bryan Nelson is Director. Azraq is a large oasis in the East Jordanian desert, a winter refuge for huge numbers of duck and wading birds, and in spring a stopping place for tens of thousands of small migrant birds. Surrounded as it is by deserts stretching away to the Saudi Arabian frontiers, the area provides the wide diversity of habitats, from lake and marsh to arid desert, that make it an excellent centre for research. An account of the area and the work of Jordanian conservationists appeared in ORYX, April 1967.

7 HERE is now considerable interest in the Azraq Oasis of the East Jordan desert. Successive British expeditions, from that of Mountfort in 1963 to that of Boyd in 1966, have placed Azraq squarely on the zoogeographical map. Its biological research potential was so apparent that Max Nicholson applied his powers of organisation to deliver, not without labour pains, an International Biological Station there in the spring of 1968. The purpose of this note is to stress the Station's existence, describe its status and state its needs.

Conservation and research are of course intimately linked and both are urgently needed at Azraq. The rapid and relatively recent decline of wildlife in Jordan is well known, and, by a fortunate convergence of circumstances, an active Jordanian Society for the Conservation of Nature, this new research station and a potentially valuable Azraq Desert National Park (at present a paper project* though Royally proclaimed) are developing in close co-operation.

The main aim of the station, which has the participation of several Jordanian Departments on its International Council, is to foster arid zone research, particularly of the kind that short expeditions, however valuable, cannot possibly do. We envisage long-term, linked studies on soil, vegetation and herbivore-grazing pressure; and productivity studies and work on the ecology of arid-zone animals and their range requirements, all of which would be immediately relevant to conservation programmes and land use in Jordan.

Secondly, perhaps less importantly but nonetheless significantly, the station exists for any scientists who want to pursue one of the many specific, short-term studies for which the wetlands and the surrounding drylands of the Azraq depression offer great opportunities. The spectacular flow of Palaearctic migrants was well shown by Ferguson-Lees and Wallace of the Boyd Expedition. At least 254 species have been reliably identified at Azraq and no fewer than 60 breed or are thought to breed in and around the oasis. There is now adequate new bungalow-type accom- 
modation at Azraq, and when the flow of visitors warrants it hotel-type services will be introduced. For scientific workers simple field laboratory facilities are backed up by more sophisticated ones at the University of Jordan.

The greatest facility is Azraq itself, for it is the combination of habitat types and their flora and fauna that offer distinctive research opportunities. So it is particularly fortunate that a large area, completely fenced, at nearby Shaumari, is available for research and experimental use by the station, at the same time as Jordan's Royal Society for the Conservation of Nature uses it for breeding gazelles, ibex and perhaps eventually oryx, ostrich and other animals. Our urgent task now is to build up a team of scientists and to get on with our research programme.

The austere beauty of the Azraq area, barren though it often is, intersected by wadis and dotted with qas (depressions in the desert that fill with water), has an individual flavour heightened by the presence of the nomadic Bedouin and their grazing animals - goats, camels etc. It would be a worthy, if not unique achievement, if scientific research, controlled hunting (for this is an immemorial hunting ground), successful repopulation with large numbers of gazelles, ibex, ostriches, bustards, etc., (which in some instances might be properly cropped for food and hence bring revenue both by hunting and selling), and finally selective tourism, could all be developed in an integrated fashion at Azraq. This would be a prototype operation which could give hope to many other impoverished but potentially valuable and interesting areas.

Biologists interested in working at Azraq should write to The Director, Jordan International Biological Station, Azraq, clo Faculty of Science, University of Jordan, Amman.

*Hemsley, J. H., and George, M.; 1966. Azraq Desert National Park, Jordan. Draft Management Plan.

\section{Somalia's Conservation Pledge}

TN a 'Manifesto on the Conservation of Nature and Natural Resources' issued in July 1968, the Government of the Somali Republic, aware of the urgent necessity for averting greater damage to the soil, flora and fauna, 'pledges itself to intensify its efforts directed towards the conservation of nature by introducing appropriate laws, establishing national parks and natural reserves, and teaching nature conservation in schools'. Somalia still has a valuable wildlife to preserve, but a report by two Italian scientists, Funaioli and Simonetta, published in 1966 and quoted in ORYX December 1967, stated that destruction was going on at such a rate that if action was not taken Somalia would be 'as bare of wildlife as any of the poorest countries of Africa'. It is encouraging to learn that the Somali government is taking action.

\section{A New Aldabra Bird}

A NEW species of warbler was discovered in Aldabra by Malcolm Penny $A$ during the Royal Society expedition in December 1967. It was named Nesillas aldabranus. Three nests were found, one with eggs. A paper on the discovery by C. W. Benson and M. J. Penny is published in the September Bulletin of the British Ornithologists' Club. 